\title{
Uncrossmatched Blood Transfusion for Resuscitation Patients at the Emergency Department
}

\author{
Korakot Apiratwarakul ${ }^{1}$, Sivit Chanthawatthanarak $^{1}$ (D), Piyathida Klawkla ${ }^{2}$ Kamonwon lenghong ${ }^{1 *}$ (D), \\ Vajarabhongsa Bhudhisawasdi ${ }^{1}$, Takaaki Suzuki ${ }^{3}$
}

${ }^{1}$ Department of Emergency Medicine, Faculty of Medicine, Khon Kaen University, Khon Kaen, Thailand; ${ }^{2}$ Department of Emergency Medicine, Bangkok Hospital Phetchaburi, Phetchaburi, Thailand; ${ }^{3}$ Department of Emergency and Critical Care Medicine, University of Tsukuba Hospital, Tsukuba, Japan

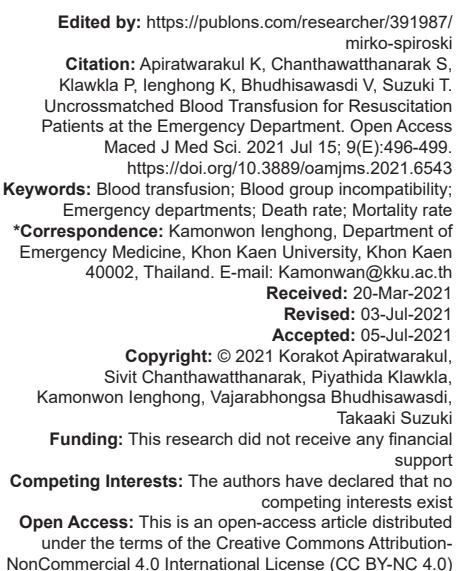
Edited by: https://publons.com/researcher/391987/ Citation: Apiratwarakul K, Chanthawatthanarak S Klawkla P, lenghong K, Bhudhisawasdi V, Suzuki Patients at the Emergency Department. Open Access Maced J Med Sci. 2021 Jul 15; 9(E):496-499. https://doi.org/10.3889/oamjms.2021.6543 Keywords: Blood transfusion; Blood group incompatibility; Emergency departments; Death rate; Mortality rate *Correspondence: Kamonwon lenghong, Department of mergency Medicine, Khon Kaen University, Khon Kaen 40002, Thailand. E-mail: Kamonwan@kku.ac.th Revised: $03-J u-2021$ Accepted: 05-Jul-2021 Copyright: ๑ 2021 Korakot Apiratwarakul, Sivit Chanthawatthanarak, Piyathida Klawkla Kamonwon lenghong, Vajarabhongsa Bhudhisawasdi,

Takaaki Suzuki
Funding: This research did not receive any financial Competing Interests: The authors have declared that no competing interests exis Open Access: This is an open-access aticle distributed under the terms of the Crealive Cons (CC BY-NC 4.0)

\begin{abstract}
BACKGROUND: Patients with uncontrolled blood loss often require immediate blood transfusion after the bleeding is stopped. If it is an emergency situation, blood that has not been tested for compatibility (uncrossmatched red blood cell [URBC] products) can be used. However, no studies have been conducted to evaluate the effectiveness of this protocol.

AIM: The aim of the study is to evaluate the effectiveness of URBC transfusion in Srinagarind Hospital's emergency department (ED).

METHODS: This was a cross-sectional study that reviewed the medical records of ninty Thai patients over 18 years of age who received at least one unit of blood through URBC transfusion in the Srinagarind Hospital ED from September 2016 to August 2018.

RESULTS: The average age of the patients was $47.23 \pm 18.2$ years, and $73.3 \%$ were male. A total of 149 units of URBC were provided, with $54.44 \%$ of recipients being trauma patients and $27.78 \%$ being gastrointestinal bleeding patients. The 24-h and in-hospital mortality rates were 58.89 and $72.22 \%$, respectively. There were no cases of acute
\end{abstract} blood transfusion complications or inappropriate URBC transfusion.

CONCLUSIONS: The transfusion of URBC necessary in patients with uncontrolled bleeding. No complications were found due to acute blood transfusion.

\section{Introduction}

Thailand is ranked among the countries with the highest mortality rate from traffic accidents, representing 20 to 24.9 people/100,000 population [1]. The main causes of death in accident patients, especially within the first $48 \mathrm{~h}$, are hemorrhage [2], [3] and coagulopathy at arrival to the hospital [4]. Treatment of blood loss consists of stopping the bleeding and performing a blood transfusion. If transfusion is performed at the earliest stages of injury, it can help reduce the risk of volume depletion, acidosis, diluted blood, and abnormal blood clotting [4], [5]. According to the advanced trauma life support guidelines $\left(10^{\text {th }}\right.$ edition), if the patient still is experiencing a large amount of blood loss or is in shock after receiving at least one liter of fluids, they should receive type-specific blood. However, in an emergency situation in which there is no time to prepare typespecific blood, O Rh-negative blood that has not been tested for compatibility (uncrossmatched red blood cells [URBC]) may be used [6]. Srinagarind Hospital began implementing guidelines for uncrossmatched blood transfusion using leukocyte-poor red cells (group $\mathrm{O}$ $\mathrm{Rh}-$ ) in the emergency room in August 2016. According to these guidelines, URBC transfusion should be performed in accident patients with hemorrhagic shock of grade 3 or higher [7], cardiac arrest, or ABC (assessment of blood consumption) scores $\geq 2$ [8]. This study was conducted to evaluate the effectiveness of this protocol at Srinagarind Hospital's emergency department (ED).

\section{Methods}

This was a cross-sectional study. The sample consisted of ninty patients over 18 years of age who received at least one unit of URBC transfusion in the Srinagarind Hospital ED from September 2016 to August 2018. Ethics approval was provided by The Khon Kaen University Ethics Committee for Human Research (HE611508). The sample size was calculated based on the proportion of URBC transfusions reported 
in a previous study by Harris et al [3]. In order to achieve a significance level of $5 \%$ and power of test of 0.8 , we determined that a sample size of 90 would be required.

Data were retrieved from medical records and hospital databases. The primary outcomes were 24-h and in-hospital mortality rates of patients who received URBC transfusion. Secondary outcomes included length of hospital stay, the amount of fluids received in the ED, and total blood received in $24 \mathrm{~h}$.

Statistical analysis was performed using SPSS for Windows version 16.0 (SPSS Inc., Chicago, IL, USA). Categorical data were presented as percentages, and continuous data were presented using mean and standard deviation. Univariable analysis was performed using a two-sample t-test for numerical data and a Pearson's correlation for data relationships between the two groups.

\section{Results}

Ninety patients were examined, the characteristics of whom are shown in Table 1. The average age was $47.23 \pm 18.2$ years, and $73.3 \%$ ( $n=66$ ) were male. Trauma and non-trauma patients accounted for $54.44 \%$ and $45.56 \%$, respectively, of the studied population. Patients with hemodynamic instability (first blood pressure measurement $<90 \mathrm{mmHg}$ ) accounted for $68.89 \%$. The median of the Glasgow coma score was 6 , and $80.0 \%$ of patients received endotracheal intubation. There were 51 cases of cardiac arrest, 35 of which occurred outof-hospital. A total of 149 units of URBC was used, $22.22 \%$ for massive transfusion and 4.6 units for total blood transfusion within $24 \mathrm{~h}$. The median volume

Table 1: Characteristics of patients receiving URBC transfusion

\begin{tabular}{ll}
\hline Characteristics & Number (\%) \\
\hline Age, mean (range) years & $47.23(16-90)$ \\
Male & $66(73.3)$ \\
Trauma & $49(54.44)$ \\
Blunt & $46(45.56)$ \\
Penetrating & $3(3.33)$ \\
Nontrauma & $41(45.56)$ \\
Gastrointestinal bleeding & $25(27.78)$ \\
Ruptured hepatocellular carcinoma & $7(7.78)$ \\
Massive hemoptysis & $3(3.33)$ \\
Ruptured aneurysms & $2(2.22)$ \\
Obstetrics-related & $2(2.22)$ \\
Medical anemia & $1(1.11)$ \\
Hematuria & $1(1.11)$ \\
Hemodynamic instability & $62(68.89)$ \\
Glasgow coma score, median (range) & $6(3-15)$ \\
Endotracheal tube intubation & $72(80)$ \\
Cardiac arrest & \\
Out hospital & $35(68.62)$ \\
In hospital & $16(31.38)$ \\
URBC units in ED, mean \pm SD & $149 \pm 1.66$ \\
Massive transfusion & $20(22.22)$ \\
Total URBC in 24 h, median (range) units & $4.6(1-33)$ \\
Volume of intravenous resuscitation at ED, median (range) ml & $2000(1000-3000)$ \\
Mortality within 24 h & $53(58.89)$ \\
Mortality, in-hospital & $65(72.22)$ \\
Time in ED, median (range) minutes & $120(90-180)$ \\
Length of stay, mean (range) days & $4.36(0-39)$ \\
Emergency surgery & $38(42.22)$ \\
Infection complication & $21(23.33)$ \\
\hline URBC: Uncrossmatched red blood cell, ED: Emergency department. & \\
&
\end{tabular}

of fluid that patients received in the ED was 2,000 milliliters. The mortality rates in the first $24 \mathrm{~h}$ and in-hospital were $58.89 \%$ and $72.22 \%$, respectively. The median duration in the ED was $120 \mathrm{~min}$ and hospitalization was 4.36 days. A total of $42.22 \%$ of patients underwent surgery or stopped bleeding in the operating room, and $23.33 \%$ experienced infectionrelated complications. There were no reports of acute intravascular hemolytic reaction.

A total of 53 patients, the majority of whom were male, died within $24 \mathrm{~h}$ (Table 2) mostly from trauma. A significantly higher number of patients in this group had severe signs, low systolic blood pressure $(p<0.001)$, low heart rate $(p=0.014)$, arterial blood $\mathrm{pH}$ lower than $7.2(p=0.005)$, low Glasgow coma score $(p<0.001)$, history of cardiac arrest, had used vasopressor drugs $(p<0.001)$, underwent endotracheal tube intubation $(p<0.001)$, and were administered a greater number of intravenous fluids at the ED $(p<0.001)$.

The 24-h mortality rates of patients who received one, two, and three units of URBC were $54,54.55$, and $76.47 \%$, respectively, and in-hospital mortality rates were $66,72.73$, and $88.24 \%$, respectively (Table 3). Although the mortality rates were higher in patients who received two or three units than those who received only one, this difference was not statistically significant.

\section{Discussion}

The transfusion of URBC is considered absolutely necessary in patients who lose large amounts of blood or experience uncontrolled shock. According to a previous study by Harris et al., trauma patients are the most likely to received URBC [3], [9]. We found that the rate of URBC transfusion in the non-trauma group was relatively high, with most being gastrointestinal bleeding patients. This may due to Srinagarind Hospital having a smaller proportion of trauma patients compared to non-trauma patients. No acute intravascular hemolytic reaction occurred after URBC transfusion, which is consistent with the findings of a previous study [10], [11] and confirms the safety of URBC transfusion [12].

However, patients in our study who received URBC in the ED had a higher mortality rate than in previous studies. The 24-h and in-hospital mortality rates in all patients were $58.89 \%$ and $72.22 \%$, respectively, compared to $26.6 \%$ in a study by Harris et al. [3]. Trauma patients had an even higher 24-h mortality rate, compared to only 28 to $47.55 \%$ in previous studies [13], [14]. This is likely because the patients in this study had more severe trauma, were more likely to have a history of endotracheal intubation and had very 
Table 2: Transfusion data by 24-h mortality

\begin{tabular}{|c|c|c|c|}
\hline Characteristics, number (\%) & Survived $24 \mathrm{~h}$ & Died within $24 \mathrm{~h}$ & $p$-value \\
\hline Number & 37 & 53 & \\
\hline Age, mean $\pm S D$ years & $44.11 \pm 17.89$ & $49.42 \pm 18.25$ & 0.175 \\
\hline Male & $20(54.05)$ & 46 (86.79) & 0.001 \\
\hline \multicolumn{4}{|l|}{ Etiology } \\
\hline Trauma & $15(40.54)$ & $34(64.15)$ & 0.027 \\
\hline Non trauma & $22(59.46)$ & $19(35.85)$ & \\
\hline URBC units in ED, mean \pm SD & $1.49 \pm 0.69$ & $1.77 \pm 0.89$ & 0.104 \\
\hline Total URBC in $24 \mathrm{~h}$, mean $\pm \mathrm{SD}$ & $5.11 \pm 4.40$ & $4.40 \pm 5.67$ & 0.513 \\
\hline Massive transfusion & $8(21.62)$ & $12(22.64)$ & 0.909 \\
\hline Systolic blood pressure $<90 \mathrm{mmHg}$ & $17(45.95)$ & $44(83.02)$ & $<0.001$ \\
\hline Heart rate, median (range) & $102(69-116)$ & $0(0-113)$ & 0.014 \\
\hline Hematocrit (\%), median (range) & $27(21-35)$ & $30(24-39)$ & 0.240 \\
\hline Platelet $<100,000$ & 11 (29.73) & $19(35.85)$ & 0.545 \\
\hline INR $>1.5$ & $12(32.43)$ & $19(35.85)$ & 0.737 \\
\hline $\mathrm{pH}<7.2$ & $18(48.65)$ & $41(77.36)$ & 0.005 \\
\hline Glasgow coma score, median (range) & $15(6-15)$ & $3(3-9)$ & $<0.001$ \\
\hline \multicolumn{4}{|l|}{ Cardiac arrest } \\
\hline Out-of-hospital & $5(13.51)$ & $30(56.60)$ & $<0.001$ \\
\hline In-hospital & $2(5.41)$ & $14(26.42)$ & 0.010 \\
\hline Vasopressor & $18(48.65)$ & $48(90.57)$ & $<0.001$ \\
\hline Tranexamic acid or Vitamin $\mathrm{K}$ & $20(54.05)$ & $18(33.96)$ & 0.058 \\
\hline Endotracheal tube intubation & $21(56.76)$ & $51(96.23)$ & $<0.001$ \\
\hline Time in ED, median (range) min & $130(100-205)$ & $120(90-180)$ & 0.245 \\
\hline Volume of intravenous fluids at ED (ml), median (range) & $2000(1000-2000)$ & $3000(2000-3000)$ & $<0.001$ \\
\hline Emergency surgery & $29(78.38)$ & $9(16.98)$ & $<0.001$ \\
\hline
\end{tabular}

Table 3: Patient's mortality rate

\begin{tabular}{|c|c|c|c|c|c|c|c|}
\hline No. of URBC & No. of patients & 24-h mortality, \% & Odd ratio $(95 \% \mathrm{Cl})$ & $p$-value & In hospital mortality, \% & Odd ratio $(95 \% \mathrm{Cl})$ & p-value \\
\hline 1 & 50 & 54 & & & 66 & & \\
\hline 2 & 22 & 54.55 & $1.022(0.37-2.79)$ & 0.966 & 72.73 & $1.373(0.45-4.15)$ & 0.574 \\
\hline 3 & 17 & 76.47 & $2.768(0.79-9.67)$ & 0.111 & 88.24 & $3.863(0.79-18.89)$ & 0.095 \\
\hline 4 & 1 & 100 & & & & & \\
\hline Overall mortal & & $53(58.89)$ & & & $65(72.22)$ & & \\
\hline
\end{tabular}

low Glasgow coma scores. We also found that both 24-h and in-hospital mortality rates increased with the amount of URBC transfused, which is consistent with the results of previous studies [2], [5]. However, this increase was not statistically significant, which may be the result of the small number of patients in each group or the fact that blood received per person is not small compared to those in a previous study [2]. We also found that the number of massive transfusions did not differ significantly between patients who survived and those who died within $24 \mathrm{~h}$. The overall number of patients who underwent massive transfusion [9] was similar to that in the study by Harris et al [3] (about $25 \%)$.

This study was limited in that the data collected from medical charts may have been incomplete [15], [16], [17], [18], [19] and that the number of trauma patients included was quite small compared to other studies. Because URBC transfusion is performed at the discretion of the physician, some patients may not have received URBC or may have received blood that does not meet the criteria.

\section{Conclusion}

The transfusion of URBC is often necessary for patients with uncontrolled bleeding. No complications due to acute blood transfusion were found.

\section{Acknowledgments}

The authors would like to thank Kaewjai Thepsuthammarat for her data analysis and statistical review and Dylan Southard for acting as English consultant.

\section{References}

1. American College of Surgeons' Committee on Trauma Advanced Trauma Life Support (ATLS). $10^{\text {th }}$ ed. Chicago: American College of Surgeons; 2017. p. 52-5.

2. Inaba K, Teixeira P, Shulman I, Nelson J, Lee J, Salim A et al. The impact of uncross-matched blood transfusion on the need for massive transfusion and mortality: analysis of 5,166 uncross-matched units. J Trauma. 2008;65(6):1222-6. http://doi. org/10.1097/TA.0b013e31818e8ff3

PMid:19077605

3. Harris CT, Totten M, Davenport D, Ye Z, O'Brien J, Williams D, et al. Experience with uncrossmatched blood refrigerator in emergency department. Trauma Surg Acute Care Open. 2018;3(1):e000184. http://doi.org/10.1136/tsaco-2018-000184 PMid:30402556

4. Massive Hemorrhage and Emergency Transfusion. Professiona Education; 2016. Available from: https://professionaleducation. blood.ca/en/transfusion/clinical-guide-transfusion.

5. Ball CG, Salomone JP, Shaz B, Dente CJ, Tallah C, Anderson K et al. Uncrossmatched blood transfusions for trauma patients in the emergency department: Incidence, outcomes and 
recommendations. Can J Surg. 2011;54(2):111-5. http://doi. org/10.1503/cjs.032009

PMid:21251416

6. Murthi SB, Dutton RP, Edelman BB, Scalea TM, Hess JR. Transfusion medicine in trauma patients. Expert Rev Hematol. 2008;1(1):99-109. http://doi.org/10.1586/17474086.1.1.99 PMid:21083009

7. American College of Surgeons' Committee on Trauma. Advanced Trauma Life Support (ATLS). $9^{\text {th }}$ ed. Chicago: American college of surgeons; 2012. p. 69-70.

8. Nunez TC, Voskresensky IV, Dossett LA, Shinall R, Dutton WD, Cotton BA. Early prediction of massive transfusion in trauma: Simple as $A B C$ (assessment of blood consumption)? J Trauma. 2009;66(2):346-52. http://doi.org/10.1097/ TA.0b013e3181961c35

PMid:19204506

9. Hamidi M, Zeeshan M, Kulvatunyou N, Adun E, O'Keeffe T, Zakaria ER, et al. Outcomes after massive transfusion in trauma patients: Variability among trauma centers. J Surg Res. 2019;234:110-5. http://doi.org/10.1016/j.jss.2018.09.018 PMid:30527461

10. Kang BH, Choi D, Cho J, Kwon J, Huh Y, Moon J, et al. Efficacy of uncross-matched type o packed red blood cell transfusion to traumatic shock patients: A propensity score match study. J Korean Med Sci. 2017;32(12):2058-63. http://doi.org/10.3346/ jkms.2017.32.12.2058 PMid:29115091

11. Mulay SB, Jaben EA, Johnson P, Badjie K, Stubbs JR. Risks and adverse outcomes associated with emergency-release red blood cell transfusion. Transfusion. 2013;53(7):1416-20. http:// doi.org/10.1111/j.1537-2995.2012.03922.x

PMid:23067326

12. Goodell PP, Uhl L, Mohammed M, Powers AA. Risk of hemolytic transfusion reactions following emergency-release RBC transfusion. Am J Clin Pathol. 2010;134(2):202-6. http://doi. org/10.1309/AJCP9OFJN7FLTXDB

\section{PMid:20660321}

13. Nunez TC, Dutton WD, May AK, Holcomb JB, Young PP, Cotton BA. Emergency department blood transfusion predicts early massive transfusion and early blood component requirement. Transfusion. 2010;50(9):1914-20. http://doi. org/10.1111/j.1537-2995.2010.02682.x

PMid:20456707

14. Huang GS, Dunham CM. Mortality outcomes in trauma patients undergoing prehospital red blood cell transfusion: A systematic literature review. Int J Burns Trauma. 2017;7(2):17-26.

PMid:28533934

15. Apiratwarakul K, Phanthachai K, Gaysonsiri D, Bhudhisawasdi V, Artpru R. Airway management with the laryngeal mask airway (LMA) in emergency medical services. J Med Assoc Thai. 2021;104(Suppl 1):S8-11. https://doi.org/10.35755/ jmedassocthai.2021.S01.12131

16. lenghong K, Suzuki T, Phengsavanh A, Nasaarn T. Competency of ultrasound knowledge of laos emergency medicine residents during international elective rotation in Thailand. J Med Assoc Thai. 2021;104(Suppl 1):S20-4. https://doi.org/10.35755/ jmedassocthai.2021.S01.12138

17. lenghong K, Srikumpa $P$, Apiratwarakul K, Phungoen $P$ Gaysonsiri D, Bhudhisawasdi V. Factors associated with transfusion of uncross-matched type-O packed red cells for acute upper gastrointestinal hemorrhage. J Med Assoc Thai. 2020;103 Suppl 6:22-6.

18. Ruttanaseeha W, Serewiwattana N, lenghong $K$, Buranasakda M, Apiratwarakul K, Tiamkao S. Accuracy of triage by nurses and doctors in the emergency department. J Med Assoc Thai. 2020;103(Suppl 6):1-3.

19. Apiratwarakul $\mathrm{K}$, lenghong $\mathrm{K}$, Suzuki $\mathrm{T}$, Celebi I, Bhudhisawasdi V, Tiamkao S. Using routine ambulance inspection report application to reduce wasted time in emergency medical services. Open Access Maced J Med Sci. 2021;9(E):298-301. https://doi.org/10.3889/oamjms.2021.6022 